\title{
Electrophoretic deposition of coatings and bulk compacts using magnesium-doped aluminum oxide nanopowders
}

\author{
E.G. Kalinina ${ }^{\text {a,b,* }}$ (D), D.S. Rusakova ${ }^{\text {b }}$, E.Yu. Pikalova ${ }^{\text {b,c }}$ (D) \\ a: Institute of Electrophysics, Ural Brunch of Russian Academy of Sciences, \\ 106 Amundsena St, Yekaterinburg, 620016, Russia \\ b: Ural Federal University, 19 Mira St., Yekaterinburg, 620002, Russia \\ c: Institute of High Temperature Electrochemistry, Ural Brunch of Russian Academy of Sciences, \\ 20 Academicheskaya St., Yekaterinburg, 620137, Russia \\ * Corresponding author: jelen456@yandex.ru \\ This article belongs to the regular issue. \\ (C) 2021, The Authors. This article is published in open access form under the terms and conditions of the Creative \\ Commons Attribution (CC BY) license (http://creativecommons.org/licenses/by/4.o/).
}

\section{Abstract}

The electrophoretic deposition (EPD) of coatings and bulk compacts in a wide range of thicknesses (from 23 to $1800 \mu \mathrm{m}$ ) from stable suspensions of a magnesium-doped aluminum oxide nanopowder with subsequent sintering of samples into dense ceramics was studied. The initial nanopowder was obtained by the method of electric explosion of an Al-Mg alloy wire with a $\mathrm{Mg}$ content of $1.3 \mathrm{wt}$. \%. The study of the dispersion composition, kinetics of deaggregation under the ultrasonic treatment and zeta potential in the nanopowder-based suspensions was carried out. It was shown that a nearly linear increase in the deposited mass and thickness of EPD deposits occurred at a constant voltage of $20 \mathrm{~V}$ and an average deposition current of approximately $40 \mu \mathrm{A}$ when the deposition time was varied from 1 to 180 min. Drying of the coatings with a thickness of less than $35 \mu \mathrm{m}$ led to the formation of a net of small cracks, while drying of the bulk compacts with a thickness of more than $1 \mathrm{~mm}$ occurred without cracking. The ceramic bulk sample with a thickness of $1.2 \mathrm{~mm}$ and the density of $98.7 \%$ TD was successfully obtained by sintering at $1650{ }^{\circ} \mathrm{C}$ for $4 \mathrm{~h}$. It was characterized by a dense grain structure with an average grain size of $5 \mu \mathrm{m}$ and the presence of a small number of closed pores less than $1 \mu \mathrm{m}$ in size. Sintering of ceramics was revealed to be accompanied by the formation of a $\mathrm{MgAl}_{2} \mathrm{O}_{4}$ crystalline spinel phase, localized mainly at grain boundaries.

\section{Keywords}

aluminum oxide

nanopowder

stable suspension

zeta potential

electrophoretic deposition

Received: 06.04.2021

Revised: 02.05.2021

Accepted: 03.05.2021

Available online: 07.05.2021

\section{Introduction}

Corundum materials are widely used in many applications as high-frequency and high-voltage insulators, current inputs, resistance substrates and etc. Thus, the development of methods for the formation of dense corundum ceramics both in the form of coatings as well as bulk compacts is a relevant and challenging task of ceramic technology. The known methods of the formation of $\mathrm{Al}_{2} \mathrm{O}_{3}$ based coatings are sol-gel method [1], chemical vapor deposition $[2,3]$, pulsed laser deposition $[4,5]$, and electrophoretic deposition (EPD) [6-8]. The slip casting is known as one of the ceramic methods for producing corundum ceramics [9]. Various pressing technologies such as isostatic and magnetic-pulse pressing were applied to com- pact powdered materials [10-12]. However, the features of these methods include the difficulty to obtain uniform density and the presence of internal stresses in the material [13].

The EPD method is based on the formation of a deposited layer on an electrode from a liquid suspension under the action of an external electric field [14-17]. It is simple and cost-effective, and is characterized by high deposition rates. The advantages of the EPD method also include flexibility in regulating the thickness of the formed deposits by varying the deposition time or electrical deposition modes. In this case, the kinetics of the deposited mass growth depending on time, the formation of cracks in the deposited layer during drying, the ratio between the achieved deposit's density before and after sintering are 
the important issues to be addressed. The features of the EPD method include the difficulty of achieving a high density of the formed deposit [18] and the formation of cracks during the deposit drying [19], which is influenced by many factors: the particle size distribution in the suspension, the thickness of coatings, drying conditions, the addition of binders and plasticizers. Santanach Carreras et al. [20] revealed the existence of a critical thickness of the coating, above which cracks may appear during its drying.

The use of nanopowders is relevant in ceramic technology since it allows one to reduce the sintering temperature of ceramics [21]. However, in the EPD technology, it is necessary to take into account the necessity of obtaining stable suspensions of nanoparticles suitable for the deposition and, thus, to find a way to diminish nanoparticle aggregation in a liquid dispersion medium [22]. The use of weakly aggregated nanopowders with a spherical shape of particles obtained by the method of electric explosion of wires (EEW) [23, 24] makes it possible to avoid the use of dispersants and charging agents due to the spontaneous formation of a high zeta potential on the nanoparticles in the suspension [25]. However, during the EPD formation of the compacts, the use of suspensions based on nanopowders during the EPD formation of the compacts can be accompanied by a decrease in their density compared to those obtained using suspensions of submicron powders [18].

It is known that the addition of a small amount of $\mathrm{Mg}$ to an oxide ceramic accelerates its sintering due to diffusion processes at the grain boundaries and makes it possible to achieve a high density of the sintered samples [2628 ]. In [28], the bulk ceramics of $98.5-99.2 \%$ of theoretical density (TD) were obtained by the EPD method from the suspensions of commercial submicron (330 and $470 \mathrm{~nm}) \mathrm{Al}_{2} \mathrm{O}_{3}$ powders with an addition of $0.05 \mathrm{wt}$. $\%$ $\mathrm{MgO}$.

The aim of this work was to study the conditions for obtaining EPD deposits in a wide range of thicknesses (from 23 to $1800 \mu \mathrm{m}$ ) from stable suspensions of EEW nanopowder of $\mathrm{Mg}$-doped $\mathrm{Al}_{2} \mathrm{O}_{3}(22 \mathrm{~nm})$ with subsequent sintering of samples into dense ceramics. The preparation of suspensions without the introduction of dispersants and binders was identified in this study as a necessary condition to obtain the EPD deposits with high green densities (the density of as-obtained deposits). The developed technology allowed obtaining the bulk ceramics of high quality with the density of $98.7 \%$ TD.

\section{Experimental}

An initial $\mathrm{Mg}$-doped $\mathrm{Al}_{2} \mathrm{O}_{3}$ nanopowder was obtained by the EEW method from an Al-Mg alloy wire with a Mg content of $1.3 \mathrm{wt}$. $\%$ as described elsewhere [23, 29]. The morphology of aluminum oxide nanoparticles was studied using a JEOL JEM 2100 transmission electron microscope (TEM) (JEOL, Tokyo, Japan). X-ray phase analysis was car- ried out on a D8 DISCOVER diffractometer (Bruker UK Ltd, Durham, UK) in a copper radiation with a graphite monochromator on a diffracted beam. The processing of the XRD data was carried out using the TOPAS-3 program. The specific surface area was determined by the volumetric version of the BET method by a low-temperature equilibrium sorption of nitrogen vapor from a mixture with helium using a Micromeritics TriStar 3000 device (Micromeritics Instrument Corporation, Norcross, USA).

The initial $\mathrm{Mg}$-doped $\mathrm{Al}_{2} \mathrm{O}_{3}$ nanopowder was used for the preparation of suspensions for the EPD in isopropanol (high purity grade). Ultrasonic treatment of the suspensions was performed using an UZV-13/150-TN ultrasonic bath (Reltek, Yekaterinburg, Russia) for $125 \mathrm{~min}$. Removal of large aggregates preserved in the suspension after the ultrasound processing was carried out by centrifugation using a Hermle $\mathrm{Z} 383$ centrifuge at a speed of $6000 \mathrm{rpm}$ for $3 \mathrm{~min}$. The electrokinetic zeta potential and $\mathrm{pH}$ in suspensions were measured by the electroacoustic method using a DT-300 analyzer (Dispersion Technology, NY, USA). Particle size distribution in suspensions was obtained by dynamic light scattering (DLS) using a ZetaPlus particle size analyzer (Brookhaven Instruments Corporation, NY, USA). All measurements in suspensions were carried out under isothermal conditions in air at $25^{\circ} \mathrm{C}$.

Electrophoretic deposition was performed in a constant voltage mode in a cell with a vertical arrangement of electrodes for the EPD of coatings and with a horizontal arrangement of electrodes for the EPD of compacts. An aluminum foil disk of $12 \mathrm{~mm}$ in diameter served as an electrode (cathode) for the deposition, the counter electrode (anode) was a stainless steel disk of the same diameter, the distance between the electrodes was $10 \mathrm{~mm}$. During the EPD, the voltage on the electrodes was set at $20 \mathrm{~V}$; the deposition time varied from 1 to $180 \mathrm{~min}$. The suspension was pumped from the bottom of the cell to its upper part for the deposition. The resulting deposits were dried on the electrode for several days in a desiccator with a small amount of isopropyl alcohol. The thickness of the dried coatings and bulk compacts was in a range of $23-1800 \mu \mathrm{m}$. The morphology of the dried EPD deposits was examined using an ST-VS-520 (Russia) optical microscope.

The bulk compacts were sintered in air at a temperature of $1650{ }^{\circ} \mathrm{C}$ for $4 \mathrm{~h}$ using a Nabertherm LHT-04/18 oven (Nabertherm GmbH, Lilienthal, Germany). Study of the microstructure of the sintered bulk samples and the EDX analysis were performed using a TESCAN MIRA 3 LMU field-emission electron microscope (TESCAN, Brno, Czech Republic) equipped with an INCA Energy $350 \mathrm{mi}-$ croanalysis system (Oxford Instruments, Abingdon, UK). The deposition of conductive carbon coatings to improve the recording quality (thickness $<10 \mathrm{~nm}$ ) was carried out using a Q150T ES system (Quorum Technologies Ltd., East Sussex, UK). The density of the sintered bulk ceramic samples was determined by the method of hydrostatic weighing. 


\section{Results and Discussion}

\subsection{Preparation and study of the dispersion composi- tion and electrokinetic properties of the suspensions}

In agreement with the TEM data, the particles of the initial $\mathrm{Mg}$-doped $\mathrm{Al}_{2} \mathrm{O}_{3}$ nanopowder were of spherical shape (Fig. 1a).

The particle size distribution (Fig. $1 b$ ) is characterized by a lognormal function:

$$
f(D)=\frac{1}{D \sigma \sqrt{2 \pi}} e^{-\frac{(\ln D-\ln \mu)^{2}}{2 \sigma^{2}}}
$$

where $D$ - particle diameter, $\mu$ - mean value of the distribution, $\sigma$ - dispersion of the normal distribution of the logarithm of diameter. The parameters' values are $\mu=19.0 \mathrm{~nm}$ and $\sigma=0.632$. According to the distribution data (Eq. 1), the average diameter of nanoparticles was $22 \mathrm{~nm}$. The specific surface of the nanopowder $\left(S_{\mathrm{BET}}\right)$ was determined to be equal to $40 \mathrm{~m}^{2} / \mathrm{g}$.

The analysis of the XRD data showed that the nanopowder contained four crystalline phases:

1) $\delta-\mathrm{Al}_{2} \mathrm{O}_{3}(68 \mathrm{wt}$ \%) of an orthorhombic syngony (sp. gr. P222) with the unit cell parameters $a=7.934 \AA$, $b=7.956 \AA, c=11.711 \AA$ with a coherent scattering region (CSR) value of $(18 \pm 2) \mathrm{nm}$;

2) $\gamma-\mathrm{Al}_{2} \mathrm{O}_{3}(31.3 \mathrm{wt}$. \%) of a cubic structure (sp. gr. $\mathrm{Fd} \overline{3} \mathrm{~m})$ with the unit cell parameter $a=(7.950 \pm 0.010) \AA$ and $\mathrm{CSR}=(26 \pm 2) \mathrm{nm}$;

3) $\alpha-\mathrm{Al}_{2} \mathrm{O}_{3}(0.4 \mathrm{wt}$ \%) of a rhombohedral syngony (sp. gr. $\mathrm{R} \overline{3} \mathrm{c}$ ) with the unit cell parameters $a=(4.764 \pm 0.004) \AA, c=(12.99 \pm 0.02) \AA$;

4) metallic $\mathrm{Al}(\mathrm{O} .3 \mathrm{wt}$ \%) of a cubic structure (sp. gr. $\mathrm{Fm} \overline{3} \mathrm{~m}), a=(4.054 \pm 0.004) \AA$.

To obtain a stable suspension of nanoparticles, isopropanol was used as a dispersion medium. The initial suspension with a concentration of $70 \mathrm{~g} / \mathrm{l}$ was prepared from an accurate weighed portion of the nanopowder and then subjected to the ultrasonic treatment (UST). After the UST, the dispersion characteristics and fractional composition of particle aggregates in the suspensions were evaluated. Fig. $2 a$ shows the dependence of the effective hydrodynamic diameter of the aggregates $\left(d_{e f f}\right)$ in the suspension as a function of the UST time (with continuous cooling of the suspension).

As derived from the data presented in Fig. 2a, under the UST the size of aggregates in the nanopowder suspension significantly decreases from $410 \mathrm{~nm}$ to $250 \mathrm{~nm}$. The large aggregates remaining after the UST were removed by centrifugation. The fractional composition of the suspension after the UST ( 25 and $125 \mathrm{~min}$ ) and centrifugation is shown in Fig. $2 b$. In accordance with the fractional composition data, in the initial suspension of the nanopowder (UST during $5 \mathrm{~min}$ ), the presence of three fractions of particles and their aggregates in different weight ratios was established: $90 \mathrm{~nm}$ (5 wt. \%), $420 \mathrm{~nm}$ (87 wt.\%), and $2020 \mathrm{~nm}$ (8 wt. \%). After the UST for $25 \mathrm{~min}$, the size of aggregates of the main fraction was $440 \mathrm{~nm}$ (97 wt. \%). After the UST for $125 \mathrm{~min}$ and centrifugation, the dispersion composition of the suspension was the following: $170 \mathrm{~nm}$ (44 wt. \%) and $45 \mathrm{~nm}$ (56 wt. \%). After centrifugation of the initial suspension $(70 \mathrm{~g} / \mathrm{l})$, the concentration of nanoparticles decreased down to $62 \mathrm{~g} / \mathrm{l}$.

The values of the electrokinetic zeta potential and $\mathrm{pH}$ obtained for the suspension of $\mathrm{Mg}$-doped $\mathrm{Al}_{2} \mathrm{O}_{3}$ nanoparticles are presented in Table 1 . According to the data, when the initial suspension was centrifuged the zeta potential decreased from +55 to $+48 \mathrm{mV}$ with a simultaneous decrease in $\mathrm{pH}$ from 8.1 to 7.3 , respectively. The obtained high value of the zeta potential ensures the stability of the suspensions and successful and stable implementation of the EPD process [30, 31].

Table 1 Parameters of the suspensions based on $\mathrm{Mg}$-doped $\mathrm{Al}_{2} \mathrm{O}_{3}$ nanoparticles

\begin{tabular}{lccc}
\hline Suspension & Concentration, g/l & Zeta potential, $\mathrm{mV}$ & $\mathrm{pH}$ \\
\hline Initial & 70 & +55 & 8.1 \\
$\begin{array}{l}\text { After } \\
\text { centrifugation }\end{array}$ & 62 & +48 & $7 \cdot 3$ \\
\hline
\end{tabular}
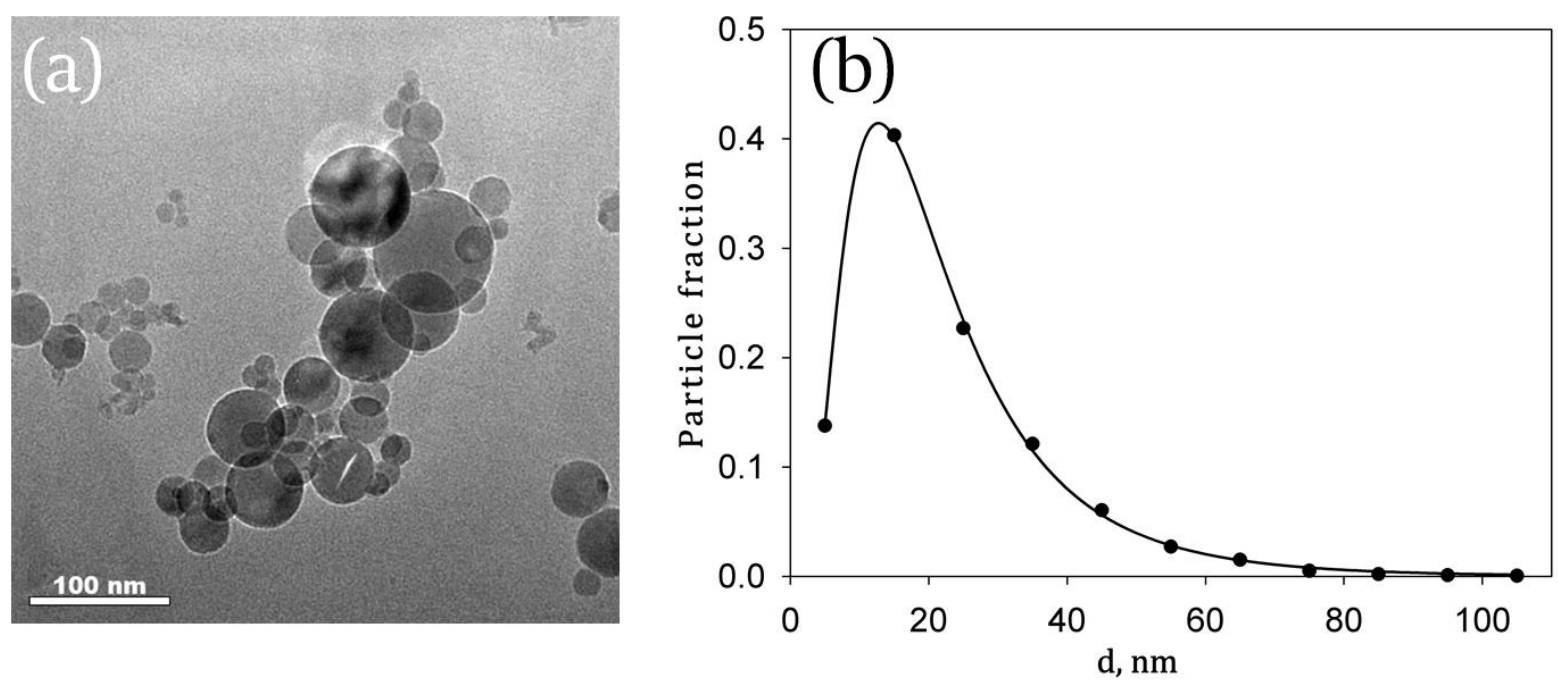

Fig. 1 Morphology of aluminum oxide nanoparticles (TEM images) (a) and numerical particle size distribution calculated using the TEM data (b) 

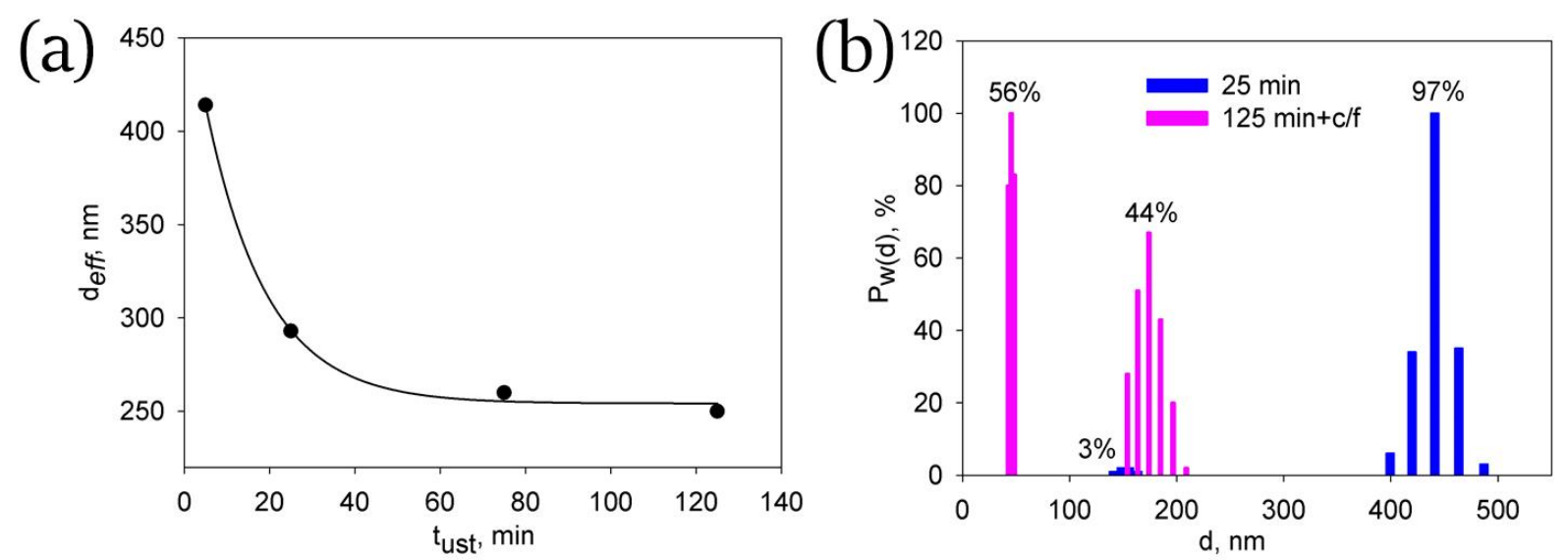

Fig. 2 Dependence of the effective hydrodynamic diameter of the aggregates on the UST time (a) and the fractional composition of the suspension with the UST for $25 \mathrm{~min}$ and $125 \mathrm{~min}$ with centrifugation (b). Pw(d) - weight fraction (\%) of particles with a diameter $d(\mathrm{~nm})$

\subsection{Electrophoretic deposition of coatings and bulk compacts}

The formation of coatings and bulk compacts was carried out from a suspension after centrifugation with a concentration of $62 \mathrm{~g} / \mathrm{l}$. The use of centrifugation made it possible to exclude a fraction of large aggregates (Fig. 2b), which is favorable for increasing the homogeneity of the resulting deposits. The characteristics of deposits obtained at different deposition times (at a constant voltage of $20 \mathrm{~V}$ and an average current of $40 \mu \mathrm{A}$ ) are shown in Table 2.

It can be seen from the data presented that almost linear dependence of the deposit thickness and weight on the deposition time is observed when obtaining coatings with a thickness of up to $35 \mu \mathrm{m}$ and during the formation of bulk compacts with a thickness of up to $1800 \mu \mathrm{m}$. It was found that the formation of cracks in the deposits during their drying is associated with their thickness. With an increase in thickness of more than $1 \mathrm{~mm}$, a compacted bulk deposit without cracks was formed, while coatings with a thickness of less than $1 \mathrm{~mm}$ tended to form a net of cracks, especially with the coating thicknesses less than $35 \mu \mathrm{m}$ (Fig. 3).

\subsection{Sintering of bulk compacts based on Mg-doped $\mathrm{Al}_{2} \mathrm{O}_{3}$ into dense ceramics}

Crack-free bulk sample AM_5 with a green thickness $1.8 \mathrm{~mm}$ (the thickness of as-obtained bulk sample deposited and dried) was sintered in air at a temperature of $1650^{\circ} \mathrm{C}$ for $4 \mathrm{~h}$. The thickness of the sintered ceramic sample was $1.2 \mathrm{~mm}$. The relative density of the AM_5 sample before sintering was about 30\% TD, while after the sintering it reached $98.7 \%$ TD. As provided by the XRD data, the sintered AM_5 ceramic sample contained two crystalline phases $2.5 \mathrm{wt} \%$ of a $\mathrm{MgAl}_{2} \mathrm{O}_{4}$ spinel phase (cubic, sp. gr. $\mathrm{Fd} \overline{3} \mathrm{~m}$ with a lattice parameter $a=(8.080 \pm 0.02) \AA$ and $\operatorname{CSR}=(110 \pm 40) \mathrm{nm})$ and $97.5 \mathrm{wt} . \%$ of a $\alpha-\mathrm{Al}_{2} \mathrm{O}_{3}$ phase (rhombohedral, sp. gr. $R \overline{3} c$ with lattice parameters $a=(4.763 \pm 0.002) \AA$, $c=(13.011 \pm 0.005) \AA$ and CSR $>200 \mathrm{~nm})$. In the initial nanopowder obtained from the Al-Mg alloy, a separate magnesium containing crystalline phase, as it was noted in the Experimental section, was not registered by the XRD analysis. Magnesium was possibly presented in the initial powder in the form of interstitial or substitutional ions in the $\mathrm{Al}_{2} \mathrm{O}_{3}$ crystal lattice. However, during longterm sintering of the compacted material into dense
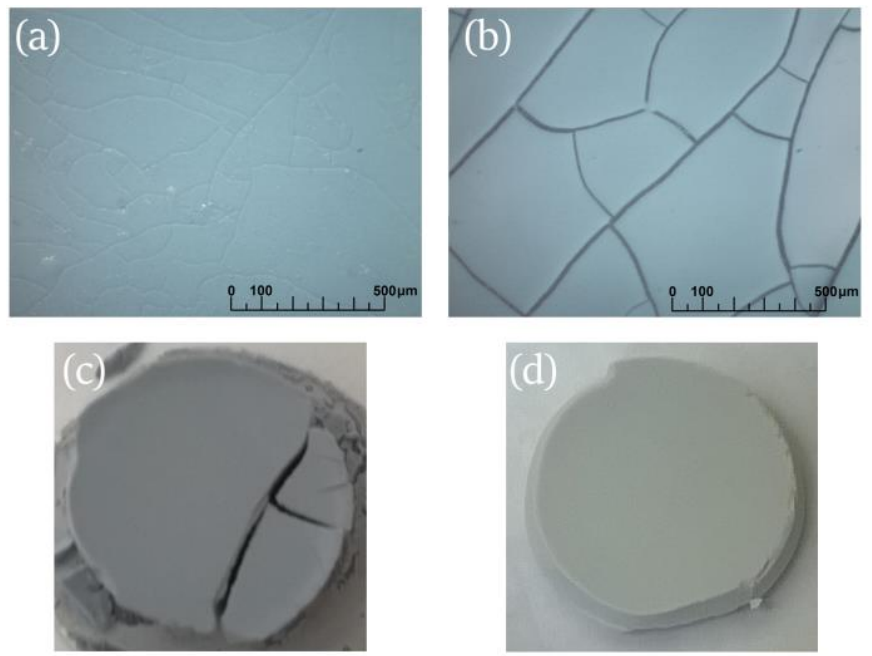

Fig. 3 Optical images of coatings and bulk compacts based on $\mathrm{Mg}$ doped $\mathrm{Al}_{2} \mathrm{O}_{3}$ : (a) sample AM_1; (b) sample AM_3; (c) sample AM_4; (d) sample AM_5

Table 2 Parameters of coatings and bulk compacts based on $\mathrm{Mg}$-doped $\mathrm{Al}_{2} \mathrm{O}_{3}$ at different deposition times (obtained at a constant voltage of $20 \mathrm{~V}$ and an average current of $40 \mu \mathrm{A}$ )

\begin{tabular}{ccccc}
\hline Sample & Deposition time, min & Weight, $\mathrm{mg}$ & Thickness, $\mu \mathrm{m}$ & Deposit characteristics \\
\hline AM_1 & 1 & 3.2 & 23 & Net of small cracks \\
AM_2 & 2 & 5.5 & 35 & Net of small cracks \\
AM_3 & 15 & 25.4 & 340 & Uniform areas of the deposit separated by cracks \\
AM_4 & 90 & 90.6 & 1000 & Single cracks in the uniform deposit \\
AM_5 & 180 & 180.8 & 1800 & Uniform deposit without cracks \\
\hline
\end{tabular}


ceramics at a temperature of $1650{ }^{\circ} \mathrm{C}$, the crystalline phase of $\mathrm{MgAl}_{2} \mathrm{O}_{4}$ spinel was formed localized mainly at the grain boundaries of the ceramics.

Fig. 4 shows electron images of the surface (a) and in section (b), as well as an integrated map (c) and individual maps of elements (d) for the sintered AM_5 ceramic sample (e). Sintered ceramics are characterized by a dense grain structure with grain sizes up to $5 \mu \mathrm{m}$ and a small number of closed pores less than $1 \mu \mathrm{m}$ in size. The element distribution map (Fig. $4 d$ ) demonstrates the segregation of magnesium along the grain boundaries. This is in good agreement with the results obtained in [26], where it was demonstrated that doping aluminum oxide with magnesium improves the sinterability of ceramics by accelerating diffusion processes at grain boundaries.

\section{Conclusions}

The study of electrophoretic deposition of coatings and bulk compacts from stable suspensions of the nanopowder of aluminum oxide doped with magnesium in an isopropyl alcohol media with subsequent sintering of samples into dense ceramics was carried out. An initial Mg-doped $\mathrm{Al}_{2} \mathrm{O}_{3}$ nanopowder was obtained by the method of electric explosion of an Al-Mg alloy wire with a Mg content of $1.3 \mathrm{wt}$. \%. A study of the dispersion composition and kinetics of ultrasonic disaggregation of aggregates in a nanopowder suspension was carried out. It was shown that the ultrasonic treatment effectively reduced the average hydrodynamic size of aggregates from 410 to $250 \mathrm{~nm}$. A fraction of large aggregates in the suspension was excluded by means of centrifugation, thus, the suspension for the EPD contained $170 \mathrm{~nm}(44 \%)$ and $45 \mathrm{~nm}(56 \%)$ fractions. The resulting suspension had a high zeta potential $(+48 \mathrm{mV})$, sufficient to ensure its stability and successful EPD. It was shown a nearly linear increase in the deposit weight and thickness observed during the EPD process at a constant voltage of $20 \mathrm{~V}$ and varying the deposition time from 1 to $180 \mathrm{~min}$. It was found that drying of coatings with a thickness of less than $35 \mu \mathrm{m}$ led to the formation of a net of small cracks. An increase in the thickness of the EPD deposit reduced cracking in such a way that drying of the samples with a thickness of more than $1 \mathrm{~mm}$ was not accompanied by their cracking. A criterion was established in concordance with that the thickness of the dried EPD deposit should be at least $1 \mathrm{~mm}$ to exclude cracks during drying in the case of the implementation of the suspension preparation scheme without the use of dispersants and binders based on EEW nanopowders, used in this study. High-quality dense ceramics $(1.2 \mathrm{~mm})$ of $98.7 \%$ TD were obtained by sintering at $1650{ }^{\circ} \mathrm{C}$ for $4 \mathrm{~h}$. Appearance of $\mathrm{MgAl}_{2} \mathrm{O}_{4}$ spinel phase on the ceramics grain boundary validates increasing sinterability of $\mathrm{Mg}$-doped corundum ceramics by accelerating diffusion processes at grain boundaries.
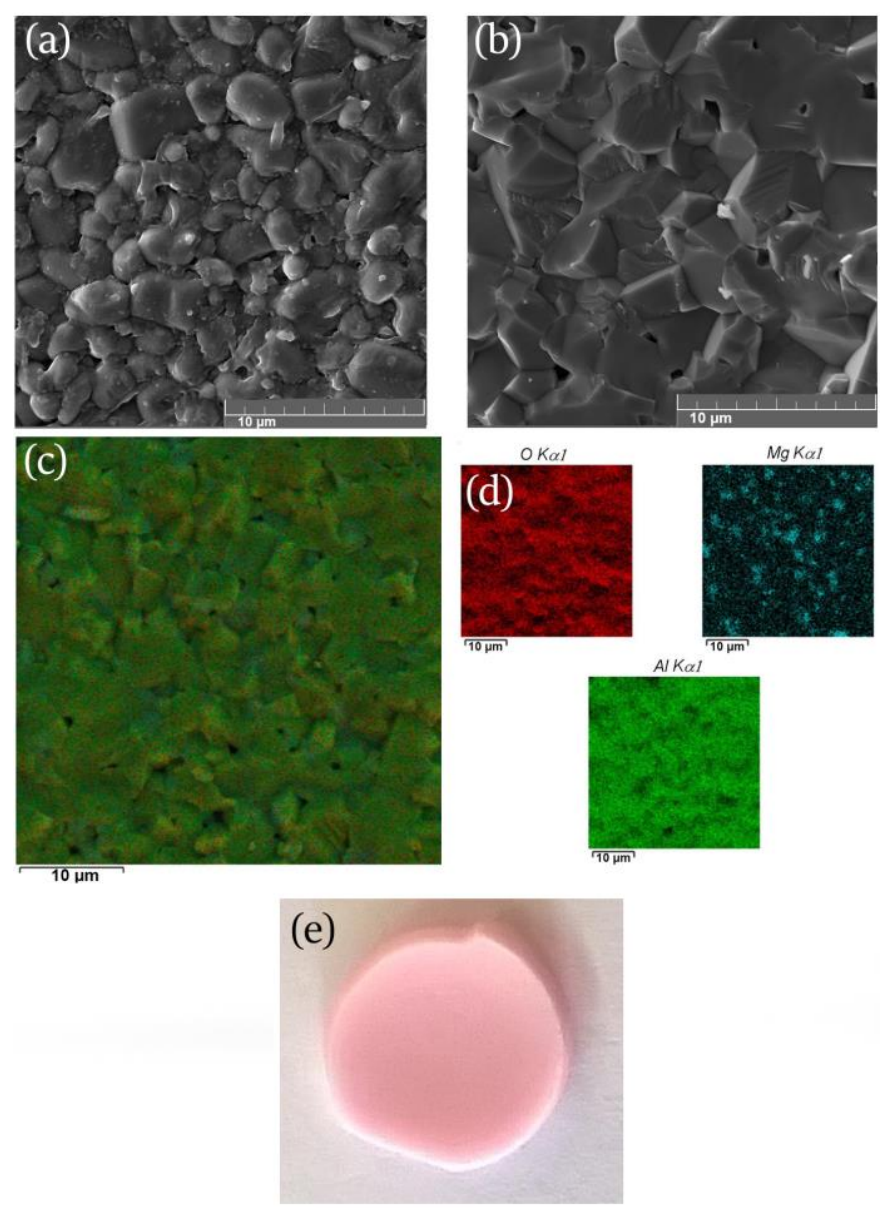

Fig. 4 Electron images of the AM_5 bulk ceramic sample sintered at a temperature of $1650^{\circ} \mathrm{C}$ for $4 \mathrm{~h}$ : surface (a) and in section (b), integrated map (c), individual maps of elements (d) and a photo of the sintered ceramic sample (e)

\section{Acknowledgements}

The work was partially carried out using the equipment of the shared access centers of the Institute of Electrophysics (IEP UB RAS) and Institute of High Temperature Electrochemistry (IHTE UB RAS), Composition of compounds. The authors are grateful to D.Sc. prof. A.P. Safronov (Ural Federal University) for valuable advice during the preparation of the manuscript, to the head of the laboratory of impulse processes Dr. I.V. Beketov and junior researcher Mr. A.V. Bagazeev (IEP UB RAS) for the development of the method for producing nanopowders (EEW method), and to scientific researcher Dr. A.S. Farlenkov (Ural Federal University) for conducting electron microscopic studies.

\section{References}

1. He J, Avnir D, Zhang L. Sol-gel derived alumina glass: Mechanistic study of its structural evolution. Acta Mater. 2019;174:418-26. doi:10.1016/j.actamat.2019.05.062

2. Kelekanjeri VG, Carter WB, Hampikian JM. Deposition of $\alpha$-alumina via combustion chemical vapor deposition. Thin Solid Films. 2006;515(4):1905-11. doi:10.1016/j.tsf.2006.07.033 
3. Ogita Y, Saito N. Formation of alumina film using alloy catalyzers in catalytic chemical vapor deposition. Thin Solid Films. 2015;575:47-51. doi:10.1016/j.tsf.2014.10.022

4. Boidin R, Halenkovič T, Nazabal V, Beneš L, Němec P. Pulsed laser deposited alumina thin films. Ceram Int. 2016;42(1):1177-82. doi:10.1016/j.ceramint.2015.09.048

5. Korhonen H, Syväluoto A, Leskinen JTT, Lappalainen R. Optically transparent and durable $\mathrm{Al}_{2} \mathrm{O}_{3}$ coatings for harsh environments by ultra short pulsed laser deposition. Opt Laser Technol. 2018;98:373-84. doi:10.1016/j.optlastec.2017.07.050

6. Kishida S, Ju D, He H, Li Y. Coating of $\mathrm{Y}-\mathrm{Al}_{2} \mathrm{O}_{3}$ on the stainless steel substrate by electrophoretic deposition method. J Environ Sci. 2009;21:S112-5. doi:10.1016/S1001-0742(og)60051-6

7. Novak S, König K. Fabrication of alumina parts by electrophoretic deposition from ethanol and aqueous suspensions. Ceram Int. 2009;35(7):2823-9. doi:10.1016/j.ceramint.2009.03.033

8. Song G, Xu G, Quan Y, Yuan Q, Davies PA. Uniform design for the optimization of $\mathrm{Al}_{2} \mathrm{O}_{3}$ nanofilms produced by electrophoretic deposition. Surf Coat Technol. 2016;286:268-78. doi:10.1016/j.surfcoat.2015.12.039

9. Takao Y, Hotta T, Naito M, Shinohara N, Okumiya M, Uematsu K. Microstructure of alumina compact body made by slip casting. J Eur Ceram Soc. 2002;22(4):397-401. doi:10.1016/S0955-2219(01)00307-7

10. Ivanov VV, Paranin SN, Khrustov VR. Nanostructured ceramics based on aluminum and zirconium oxides produced using magnetic pulsed pressing. Phys Metals Metallogr. 2002;94:S98-S106.

11. Kaygorodov A, Rhee C, Kim W, Ivanov V, Paranin S, Spirin A, Khrustov V. Nozzles from Alumina Ceramics with Submicron Structure Fabricated by Radial Pulsed Compaction. Mater Sci Forum. 2007;534-536:1053-6. doi:10.4028/www.scientific.net/MSF.534-536.1053

12. Promdej C, Pavarajarn V, Wada S, Wasanapiarnpong T, Charinpanitkul T. Effect of hot isostatically pressed sintering on microstructure of translucent alumina compact. Curr Appl Phys. 2009;9(5):96o-6. doi:10.1016/j.cap.2008.09.011

13. Okuma G, Watanabe S, Shinobe K, Nishiyama N, Takeuchi A, Uesugi K, Tanaka S, Wakai F. 3D multiscale-imaging of processing-induced defects formed during sintering of hierarchical powder packings. Sci Rep. 2019;9:11595. doi:10.1038/s41598-019-48127-y

14. Corni I, Ryan MP, Boccaccini AR. Electrophoretic deposition: From traditional ceramics to nanotechnology. J Eur Ceram Soc. 2008;28(7):1353-67. doi:10.1016/j.jeurceramsoc.2007.12.011

15. Pikalova E, Kalinina E. Place of electrophoretic deposition among thin-film methods adapted to the solid oxide fuel cell technology: A short review. J of Energy Prod and Mgm. 2019;4(1):1-27. doi:10.2495/EQ-V4-N1-1-27

16. Pikalova EYu, Kalinina EG. Electrophoretic deposition in the solid oxide fuel cell technology: Fundamentals and recent advances. Renew Sust Energ Rev. 2019;116:109440. doi:10.1016/j.rser.2019.109440

17. Kalinina EG, Pikalova EYu. New trends in the development of electrophoretic deposition method in the solid oxide fuel cell technology: theoretical approaches, experimental solutions and development prospects. Russ Chem Rev. 2019;88(12):1179-219. doi:10.1070/RCR4889
18. König K, Novak S, Boccaccini AR, Kobe S. The effect of the particle size and the morphology of alumina powders on the processing of green bodies by electrophoretic deposition. J Mater Process Technol. 2010;210(1):96-103. doi:10.1016/j.jmatprotec.2009.08.007

19. Xu P, Mujumdar AS, Yu B. Drying-Induced Cracks in Thin Film Fabricated from Colloidal Dispersions. Drying Technology. 2009;27(5):636-52. doi:10.1080/07373930902820804

20. Santanach Carreras E, Chabert F, Dunstan DE, Franks GV. Avoiding "mud" cracks during drying of thin films from aqueous colloidal suspensions. Journal of Colloid and Interface Science. $2007 ; 313(1): 160-8$. doi:10.1016/j.jcis.2007.03.076

21. Koltsov I, Smalc-Koziorowska J, Prześniak-Welenc M, Małysa M, Kimmel G, McGlynn J, Ganin A, Stelmakh S. Mechanism of Reduced Sintering Temperature of $\mathrm{Al}_{2} \mathrm{O}_{3}-\mathrm{ZrO}_{2}$ Nanocomposites Obtained by Microwave Hydrothermal Synthesis. Materials. 2018;11(5):829. doi:10.3390/ma11050829

22. Lewis JA. Colloidal Processing of Ceramics. J Am Ceram Soc. 2000;83(10):2341-59. doi:10.1111/j.1151-2916.2000.tb01560.x

23. Kotov YA. Electric Explosion of Wires as a Method for Preparation of Nanopowders. J Nanopart Res. 2003;5:539-50. doi:10.1023/B:NANO.0000006069.45073.0b

24. Kotov YA. The electrical explosion of wire: A method for the synthesis of weakly aggregated nanopowders. Nanotechnol Russia. 2009;4:415-24. doi:10.1134/S1995078009070039

25. Safronov AP, Kalinina EG, Smirnova TA, Leiman DV, Bagazeev AV. Self-stabilization of aqueous suspensions of alumina nanoparticles obtained by electrical explosion. Russ J Phys Chem A. 2010;84:2122-7. doi:10.1134/So036024410120204

26. Harun Z, Ismail NF, Badarulzaman NA. Effect of MgO Additive on Microstructure of $\mathrm{Al}_{2} \mathrm{O}_{3}$. Adv Mat Res. 2012;488-489:335-9. doi:10.4028/www.scientific.net/AMR.488-489.335

27. Pikalova EYu, Kalinina EG. Approaches to improving efficiency of solid oxide fuel cells based on ceramic membranes with mixed conductivity. Russ Chem Rev. 2021;90 In Press. doi:10.1070/RCR4966

28. Maca K, Hadraba H, Cihlar J. Electrophoretic deposition of alumina and zirconia: I. Single-component systems. Ceram Int. 2004;30(6):843-51. doi:10.1016/j.ceramint.2003.09.021

29. Kotov YuA, Beketov IV, Azarkevich EI, Murzakaev AM. Synthesis of Nanometer-Sized Powders of Alumina Containing Magnesia. In: Proceedings of the Ninth CIMTEC-World Ceramic Congress "Ceramics: Getting into the 200os", 1998 Jun 14-19; Florence, Italy. p. 277-84.

30. Bhattacharjee S. DLS and zeta potential - What they are and what they are not? J Control Release. 2016;235:337-51. doi:10.1016/j.jconrel.2016.06.017

31. Aznam I, Mah JCW, Muchtar A, Somalu MR, Ghazali MJ. A review of key parameters for effective electrophoretic deposition in the fabrication of solid oxide fuel cells. Univ Sci A. 2018;19:811-23. doi:10.1631/jzus.A1700604 